\title{
Influence of the nanolayer structure of coatings on the cutting properties of tools
}

\author{
Marina Volosova $^{1, *}$, Jury Bublikov ${ }^{2}$, Catherine Sotova ${ }^{1}$, and Ilya Sadov ${ }^{1}$ \\ ${ }^{1}$ MSTU STANKIN, Vadkovsky per. 1, Moscow, 127994, Russia \\ ${ }^{2}$ IDTI RAS, Vadkovsky per. 18-1A, Moscow, 127055, Russia
}

\begin{abstract}
The paper is focused on the influence of the thickness of nanolayers in the Ti-TiN-(Ti,Cr,Al)N coating on the cutting properties of the tools during the turning of 09G2S silicon-manganese steel. Coatings with the nanolayer thicknesses of 302,70 , and $16 \mathrm{~nm}$ were considered. The conducted studies have revealed that a tool with a coating in which the nanolayer thickness is equal to $16 \mathrm{~nm}$ demonstrates the longest tool life. At the same time, for such tool, the wear pattern is more balanced, and signs of brittle fracture on the coating are less pronounced. The Ti-TiN$(\mathrm{Ti}, \mathrm{Cr}, \mathrm{Al}) \mathrm{N}$ coating with the nanolayer thickness of $16 \mathrm{~nm}$ provides an increase in the tool life by 3.5 times compared to an uncoated tool and by 1.3-1.5 times compared to the tools with the Ti-TiN-(Ti,Cr, Al) N coating with thicker nanolayers.
\end{abstract}

\section{Introduction}

At present, the coatings with nanolayer structures are increasingly used in the manufacturing of metal cutting tools [1-16]. The coatings with the above mentioned structures have a number of obvious advantages [4,7,9-16]. Such coatings are able to more effectively suppress the processes of interdiffusion and heat transfer and are also characterized by the enhanced crack resistance [17-19]. The challenge of choosing the optimal nanolayer thickness has been studied in a number of papers [15-17,19]. In particular, it has been revealed that the nanolayer thickness does not significantly influence the hardness of the coating, but affects the wear resistance and the coefficient of friction [20-28]. It has also been found that the plastic properties of the coatings with low nanolayer thickness are not associated with dislocation displacement [25], but are associated with the sliding along grain boundaries [21]. Several papers have revealed the enhanced cutting properties of the tools with nanolayer coatings [22,29,30]. In [31], the studies were focused on the influence of the thicknesses of nanolayers in the Ti-TiN-(Ti,Al, $\mathrm{Cr}) \mathrm{N}$ coating on the tool life of a metal cutting tool during the turning of 1045 steel. It has been found that the cutting tool with the coating having a nanolayer thickness of about $16 \mathrm{~nm}$ demonstrates the best wear resistance.

At the same time, an important task is to check the validity of the results for other materials being machined. Thus, the task of the paper is to study the influence of the thicknesses of

* Corresponding author: $\underline{\text { dr.a.veres@yandex.ru }}$ 
nanolayers in the Ti-TiN-(Ti,Al,Cr)N multilayered structured coating on the wear rate of a carbide cutting tool during the turning of structural low-alloy 09G2S steel. In addition to the three major alloying elements (carbon, manganese, and silicon), the chemical composition of 09G2S steel may also include sulphur, nickel, phosphorus, nitrogen, and other additions. The total percentage of alloying elements should not exceed $1-2 \%$. Taking into account the fact that the total percentage of additions is about $2.5 \%, 09 \mathrm{G} 2 \mathrm{~S}$ is as low-alloy steel, while the presence of silicon and manganese defines 09G2S as siliconmanganese steel. 09G2S steel has the hardness of HB 450-490 MPa, and it is widely used in construction. With the density of $7.85 \mathrm{~g} / \mathrm{cm}^{3}$ after machining and obtaining a two-phase structure the steel acquires a high level of durability life with a simultaneous increase (by $3.0-3.5$ times) of cycles to structural failure.

The Ti-TiN-(Ti,Al,Cr)N coating is characterized by high hardness and wear resistance in combination with good heat resistance. Due to the above, the Ti-TiN-(Ti,Al,Cr)N coating is a good choice in the manufacturing of metal cutting tools for a wide range of application. However, in connection with the need to increase the machining efficiency and an increase in cutting speed, which causes a growth of temperature in the cutting zone, the challenge of further improvement of the performance properties of the coating is an important and urgent task.

\section{Materials and Methods}

The Ti-TiN-(Ti,Al,Cr)N multilayered nanostructured coating with a varying thickness of nanolayers in a $(\mathrm{Ti}, \mathrm{Al}, \mathrm{Cr}) \mathrm{N}$ wear-resistant layer was deposited using the VIT-2 unit [3236 , on which the filtered cathodic vacuum arc deposition (FCVAD) technology was implemented [37-42]. Depending on the turntable rotation frequency (from 0.25 to 7.0 $\mathrm{rev} / \mathrm{min}$ ), the nanolayer thickness varied during the deposition of the coatings.

A SEM FEI Quanta 600 FEG was involved in the microstructural studies of samples.

The micro- and nanostructures of the samples were analyzed using JEM 2100 highresolution transmission electron microscope (TEM) with an accelerating voltage of $200 \mathrm{kV}$. Energy-dispersive X-ray spectroscopy (EDXS) INCA Energy was applied to investigate the chemical composition of the samples.

The cutting properties of a tool with the deposited coating were studied using a CU 500 MRD SLIVEN lathe with a ZMM CU500MRD variable speed drive. Inserts of SNUN ISO 1832:2012 were used as coating substrates. The cutting tool geometry was as follows: $\gamma=-$ $7^{\circ} ; \alpha=7^{\circ} ; \lambda=0 ; \mathrm{r}=0.4 \mathrm{~mm}$; with the following cutting mode: $\mathrm{f}=0.25 \mathrm{~mm} / \mathrm{rev}, \mathrm{a}_{\mathrm{p}}=1.0$ $\mathrm{mm}, \mathrm{v}_{\mathrm{c}}=300 \mathrm{~m} / \mathrm{min}$. The limit of flank wear $\mathrm{VB}_{\max }=0.4 \mathrm{~mm}$ was assumed as a wear criterion.

\section{Results and Discussion}

The nanostructures of the coatings under study are exhibited in Fig. 1. A nanolayer structure is well distinguished on all three samples, and each nanolayer also has a complex internal structure, formed due to the planetary rotation of the toolset during the deposition of the coating $[14,31]$. The conducted studies have found that the total thicknesses of all the coatings under study are equal and reach about $4 \mu \mathrm{m}$. The coatings have a three-layer architecture which includes a Ti adhesion layer (with the thickness of about $40 \mathrm{~nm}$ ), a TiN transition layer (with the thickness of about $0.7 \mu \mathrm{m}$ ), and a (Ti,Al,Cr)N wear-resistant layer with a nanolayer structure. The advantages of such structure are discussed in more detail in [31,43-48]. An important distinctive feature of the coatings under study is the fact that while in the coatings with the nanolayer thicknesses of 302 and $70 \mathrm{~nm}$, the crystal growth is 
limited by the boundaries of the nanolayer, then in the coating with the nanolayer thickness of $16 \mathrm{~nm}$, the nanolayer boundaries do not limit the growth of crystals (see Figs $1 \mathrm{a}$ and b), and a herringbone-type hierarchical structure is formed in the coating (see Fig. 1c).

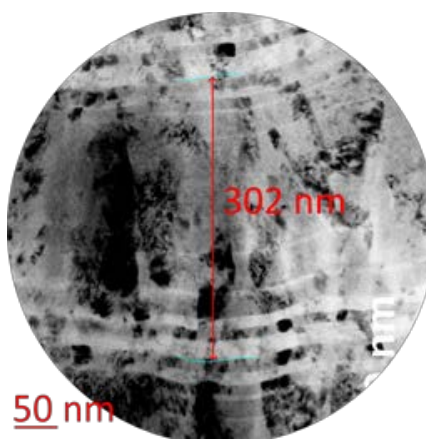

a

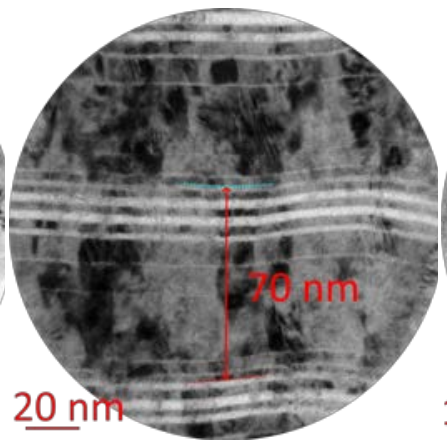

b

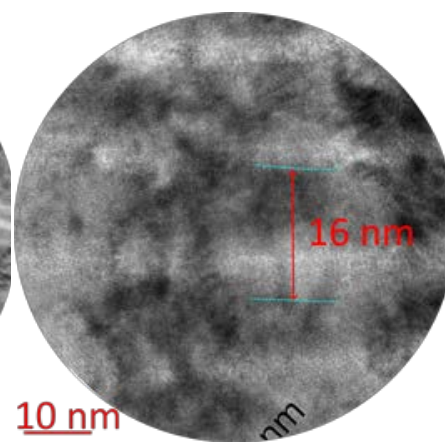

$\mathrm{c}$

Fig. 1. Nanostructures of the Ti-TiN-(Ti,Al,Cr)N coatings with different nanolayer thicknesses: $302 \mathrm{~nm}(\mathrm{a}), 70 \mathrm{~nm}$ (b) and $16 \mathrm{~nm}$ (c) (TEM)

The specific features typical for the formation of the coating crystalline structure depending on the nanolayer thickness are considered in more detail in Fig. 2. It can be seen that when the nanolayer thickness is $302 \mathrm{~nm}$, the growth of crystals is limited by internanolayer interfaces, but when the nanolayer thickness is $16 \mathrm{~nm}$, the crystal growth hardly correlates with the nanolayer structure of the coating.
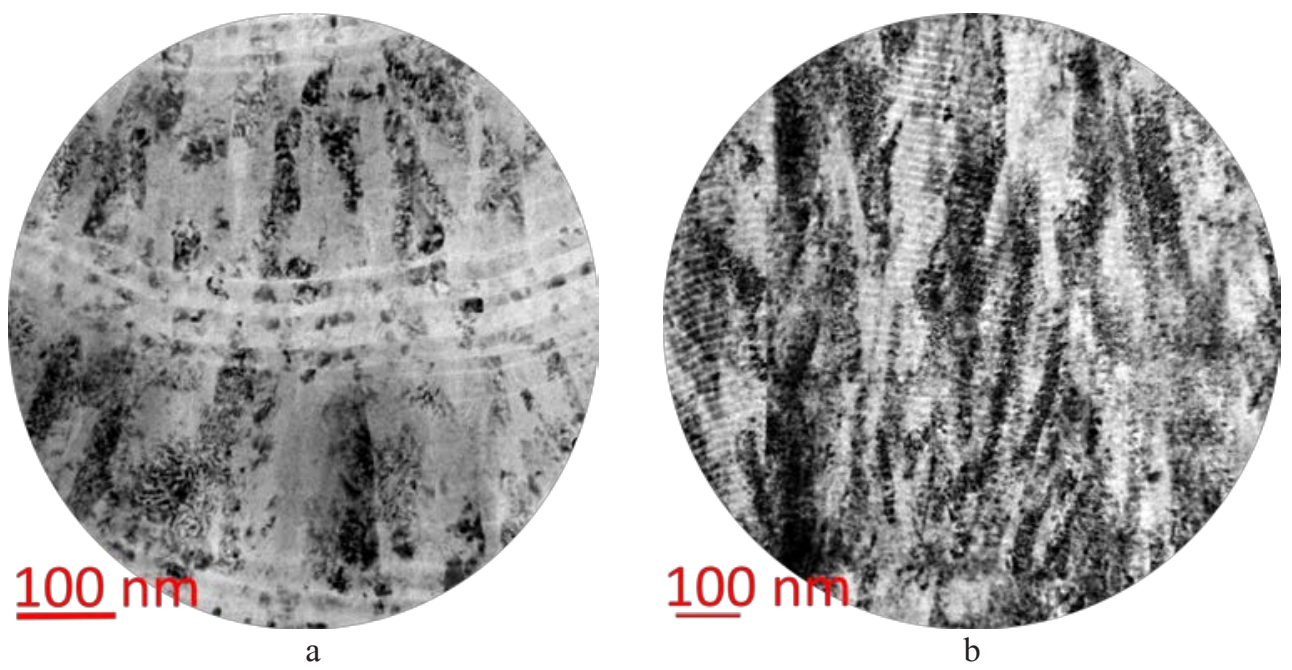

Fig. 2. Influence of the interlayer interfaces on the growth of crystals in the Ti-TiN-(Ti,Al,Cr)N coating with the nanolayer thicknesses of (a) $302 \mathrm{~nm}$ and (b) $16 \mathrm{~nm}$ (TEM)

Fig. 3 depicts the influence of the nanolayer thickness in the wear resistant layer on the rake and flank wear of carbide inserts. It can be noticed that the nanolayer thickness has the major influence on the wear rate on the rake face, while the effect on the flank face is weaker. This phenomenon can be explained by the fact that the rake face is exposed to active diffusion and oxidation wear, while adhesive and abrasive wear processes are more 
typical for the flank face. The nanolayer coating structure has a greater effect on the resistance to diffusion and oxidation wear due to the internanolayer interfaces, while the effect of the nanolayer structure to the adhesive and abrasive wear is less noticeable $[31,46,48]$.

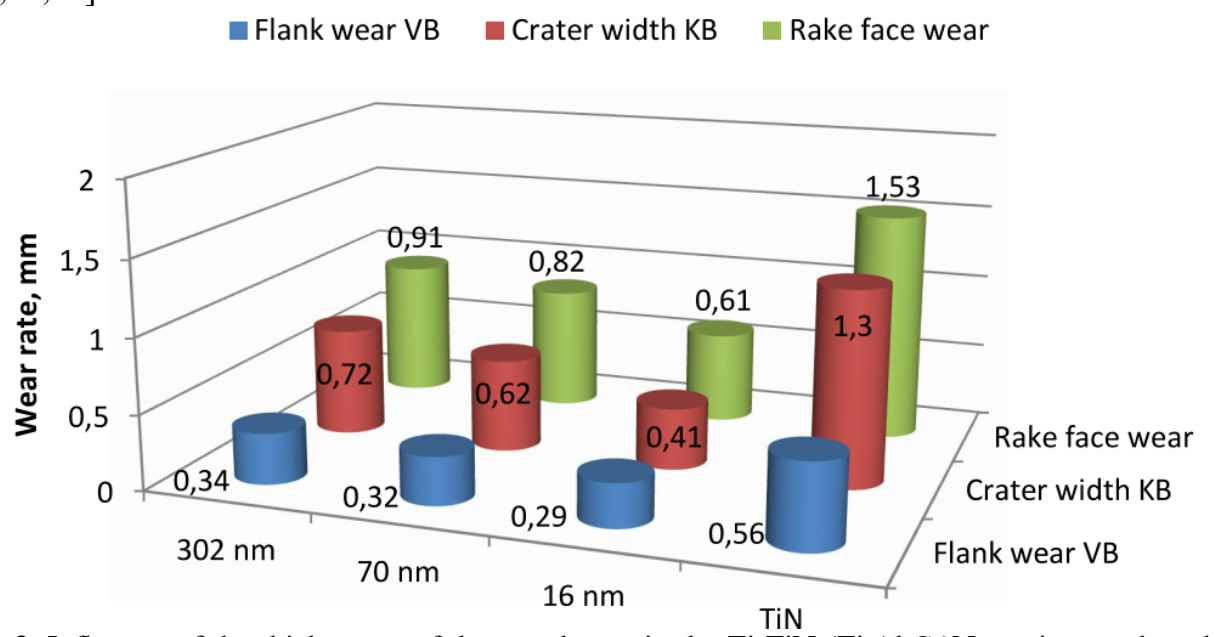

Fig. 3. Influence of the thicknesses of the nanolayers in the Ti-TiN-(Ti,Al,Cr)N coating on the rake and flank wear of carbide inserts during the turning of 09G2S silicon-manganese steel.

The study focused on the fracture pattern on the coatings during the cutting demonstrates that for the coating with the nanolayer thickness of $302 \mathrm{~nm}$, a typical process is the delamination of individual nanolayers with the formation of corresponding terracelike structures at the boundaries of the coating fracture. Meanwhile, the coating with the nanolayer thickness of $16 \mathrm{~nm}$ fails as a whole, with the formation of smooth surfaces at the fracture boundaries. For the coating with the nanolayer thickness of $70 \mathrm{~nm}$, an intermediate fracture mechanism is typical, during which no interlayer delaminations occur, but the fracture boundary is sufficiently smooth, without the formation of a terrace-like structure. flush left beneath the figures.

\section{Conclusion}

The influence of the thickness of nanolayers in the Ti-TiN-(Ti,Cr,Al)N coating on the cutting properties of the tools during the turning of 09G2S silicon-manganese steel was investigated. Coatings with the nanolayer thicknesses of 302, 70, and $16 \mathrm{~nm}$ were studied.

The conduced studies have found that:

1. For the coating with the nanolayer thickness of $302 \mathrm{~nm}$, the internanolayer interfaces inhibit the crystal growth, and the sizes of the formed crystals stay within the nanolayer thickness.

2. For the coating with the nanolayer thickness of $16 \mathrm{~nm}$, the nanolayer structure has weak influence on the formation of crystalline structure, and a through hierarchical structure of herringbone type is formed in the coating.

3. The Ti-TiN-(Ti,Cr,Al)N coating with the nanolayer thickness of $16 \mathrm{~nm}$ provides an increase in the tool life by 3.5 times compared to an uncoated tool, and by 1.3-1.5 times compared to the tools with the Ti-TiN-(Ti,Cr,Al)N coating with thicker nanolayers.

4. The wear pattern on the tool with the Ti-TiN-(Ti,Cr,Al)N coating with the nanolayer thickness of $16 \mathrm{~nm}$ is more balanced, while signs of brittle fracture are less pronounced for this coating. 
This work was funded by the state assignment of the Ministry of Science and Higher Education of the Russian Federation, project No. 0707-2020-0025

\section{References}

1. A.S. Vereschaka, Working capacity of the cutting tool with wear resistant coatings. (Mashinostroenie. Moscow, 1993)

2. K.D. Bouzakis, N. Michailidis, G. Skordaris, E. Bouzakis, D. Biermann, R. M'Saoubi, CIRP Ann. Manuf. Technol. 61, 703 (2012)

3. M. Tkadletz, N. Schalk, R. Daniel, J. Keckes, C. Czettl, C. Mitterer, Surf. Coatings Technol. 285, 31(2016)

4. M.A. Baker, S. Klose, C. Rebholz, A. Leyland, A. Matthews, Surf. Coat. Technol. 151-152, 338 (2002)

5. G. Skordaris, K.-D. Bouzakis, P. Charalampous, E. Bouzakis, R. Paraskevopoulou, O. Lemmer, S. Bolz, CIRP Ann. Manuf. Technol. 63, 93 (2014)

6. S. Zhang, D. Sun, F. Yongqing, D. Hejun, Surf. Coat. Technol.167, 113(2003)

7. J. Singh, D.E. Wolfe, J. Mater. Eng. Perform.14, 448 (2005)

8. A. Leyland, A. Matthews, Wear 246, 1 (2000)

9. A.A. Vereschaka, M.A. Volosova, S.N. Grigoriev, A.S. Vereschaka, Procedia CIRP 9, 8 (2013)

10. A. Vereschaka, M.A. Volosova, A.D. Batako, A.S. Vereshchaka, B.Y. Mokritskii, Int. J. Adv. Manuf. Technol. 84, 1471 (2016)

11. A.A. Vereschaka, A.S. Vereschaka, A.D.Batako, O.Kh.Hojaev, B.Y. Mokritskii, Int. J. Adv. Manuf. Technol. 87, 3449 (2016)

12. A.A. Vereshchaka, A.S. Vereshchaka, O. Mgaloblishvili, M.N. Morgan, A.D. Batako, Int. J. Adv. Manuf. Technol. 72(1), 303 (2014)

13. A.A Vereschaka, A.S. Vereschaka, J.I. Bublikov, A.Y. Aksenenko, N.N. Sitnikov, J. Nano Res. 40, 90 (2016)

14. A. Vereschaka, V. Tabakov, S. Grigoriev, N. Sitnikov, N. Andreev, F. Milovich, Wear. 416-417, 72 (2018)

15. P.Eh. Hovsepian, D.B. Lewis, Q. Luo, W.-D.Munz, P.H. Mayrhofer, C. Mitterer, Z. Zhou, W.M. Thin Solid Films 485, 160 (2005)

16. M. Antonov, I. Hussainova, F. Sergejev, P. Kulu, A. Gregor, Wear 267(5-8), 898 (2009)

17. A.A. Vereschaka, S.N. Grigoriev, Wear. 378-379, 43 (2017)

18. A.A. Vereschaka, S.N. Grigoriev, M.A. Volosova, A. Batako, A.S. Vereschaka, N.N. Sitnikov, A.E. Seleznev, Int. J. Adv. Manuf. Technol. 90(1-4), 27 (2017)

19. A. Vereschaka, A. Aksenenko, N. Sitnikov, M. Migranov, S. Shevchenko, C. Sotova, A. Batako, N. Andreev. Tribol. Int. 128, 313 (2018)

20. E. Contreras, Y. Galindez, M.A. Rodas, G. Bejarano, M.A. Gómez. Surf. Coat. Technol. 332, 214 (2017)

21. K. Bobzin, T. Brögelmann, N.C. Kruppe, M. Arghavani, J. Mayer, T.E. Weirich. Surf. Coat. Technol. 332, 253 (2017)

22. P.Eh. Hovsepian, A.P. Ehiasarian, A. Deeming, C. Vacuum 82, 1312 (2008) 
23. Z.G. Zhang, O. Rapaud, N. Allain, D. Mercs, M. Baraket, C. Dong, C. Coddet. Appl. Surf. Sci. 255, 4020 (2009)

24. J.A. Araujo, G. M. Araujo, R. M. Souza, A. P. Tschiptschin. Wear 330-331,469 (2015)

25. J. A. Araujo, R. A. R.Giorjao, J. Bettini, R. M. Souza, A. P. Tschiptschin. Surf. Coat. Technol. 308, 264 (2016)

26. G. Kamath, A.P. Ehiasarian, Y. Purandare, P.Eh. Hovsepian. Surf. Coat. Technol. 205, 2823 (2011)

27. P.Eh. Hovsepian, A.P. Ehiasarian, R. Braun, J. Walker, H. Du. Surf. Coat. Technol. 204, 2702 (2010)

28. M.A. Al-Bukhaiti, K.A. Al-Hatab, W. Tillmann, F. Hoffmann, T. Sprute. Appl. Surf. Sci. 318, 180 (2014)

29. Y-H. Yanga, I-W. Yeob, S-J. Parkc, Y-S. Oh. Ceram. Int. 40, 11567 (2014)

30. M. Wang, T.Toihara, M.Sakurai, W.Kurosaka, S.Miyake. Tribol. Int. 3, 36 (2014)

31. A.Vereschaka, V. Tabakov, S. Grigoriev, N. Sitnikov, F. Milovich, N. Andreev, , C. Sotova, N. Kutina, Surf. Coat. Technol. 385, 125402 (2020)

32. V. Alexey, Key Eng. Mater. 581(2014) 62-67

33. M.A. Volosova, S.N. Grigor'ev, V.V. Kuzin, Refract Ind Ceram 56, 91 (2015)

34. A. Metel, V. Bolbukov, M. Volosova, S. Grigoriev, Yu. Melnik. Instrum. Exp. Tech. 57(3), 345 (2014)

35. S.N. Grigoriev, O.V. Sobol, V.M. Beresnev, I.V. Serdyuk, A.D. Pogrebnyak, D.A. Kolesnikov, U.S. Nemchenko, J. Frict. Wear 35(5), 359 (2014)

36. O. V. Sobol', A. A. Andreev, S. N. Grigoriev, V.F. Gorban', M.A. Volosova, S.V. Aleshin, V.A. Stolbovoy, Probl. At. Sci. Technol. 4, 174 (2011)

37. V.V. Kuzin, S.N. Grigor'ev, M.A. Volosova, Refract. Ind. Ceram. 54, 376 (2014)

38. V.V. Kuzin, S.N. Grigoriev, M.Yu. Fedorov, J. Frict. Wear. 36(1), 40 (2015)

39. A.A. Vereschaka, S.N. Grigoriev, N.N. Sitnikov, G.V. Oganyan, A. Batako, Surf. Coat. Technol. 332, 198 (2017)

40. A.S. Metel, S.N. Grigoriev, Yu.A. Melnik, V.P. Bolbukov, Instrum. Exp. Tech. 55(1), 122 (2012)

41. A. Metel, V. Bolbukov, M. Volosova, S. Grigoriev, Y. Melnik, Surf. Coat. Technol 225, 34 (2013)

42. S. Grigoriev, Y. Melnik, A. Metel, Broad fast neutral molecule beam sources for industrial scale beam-assisted deposition. Surf. Coat. Technol. 156(1-3), 44 (2002)

43. V. Alexey, Adv Mat Res 712-715, 347 (2013)

44. A.S. Vereschaka, S.N. Grigoriev, V.P. Tabakov, E.S. Sotova, A.A. Vereschaka, M.Yu. Kulikov, Key Eng. Mater. 581, 68 (2014)

45. A.S. Vereshchaka, A.A. Vereshchaka, A.K. Kirillov, Key Eng. Mater. 496, 67 (2012)

46. A. Vereschaka, V. Tabakov, S. Grigoriev, N. Sitnikov, G. Oganyan, N. Andreev, F. Milovich, Wear 420-421, 17 (2019)

47. A. Vereschaka, S. Grigoriev, N. Sitnikov, F. Milovich, A. Aksenenko, N. Andreev. Int. J. Adv. Manuf. Technol. 102(9-12), 2953 (2019)

48. A.A. Vereschaka, V. Tabakov, S. Grigoriev, A. Aksenenko, N. Sitnikov, G. Oganyan, A. Seleznev, S. Shevchenko, Surf. Coatings Technol. 357, 218 (2019) 